Review Article

\title{
Driving Safety Analysis Using Grid-Based Water-Filled Rut Depth Distribution
}

\author{
Jiao Yan (D), ${ }^{1}$ Hongwei Zhang, ${ }^{2,3}$ and Bing Hui ${ }^{4}$ \\ ${ }^{1}$ School of Vehicle Engineering, Xi'an Aeronautical University, Xi'an, Shaanxi, China \\ ${ }^{2}$ Key Laboratory of Road Structure and Materials of Inner Mongolia, Hohhot, China \\ ${ }^{3}$ Inner Mongolia Communications Construction Engineering Quality Supervision Bureau, Hohhot, China \\ ${ }^{4}$ School of Highway, Chang'an University, Middle Section of Nan Erhuan Road, Xi'an, Shaanxi, China \\ Correspondence should be addressed to Jiao Yan; 201901006@xaau.edu.cn
}

Received 29 January 2021; Accepted 23 March 2021; Published 5 April 2021

Academic Editor: Jun Liu

Copyright $\odot 2021$ Jiao Yan et al. This is an open access article distributed under the Creative Commons Attribution License, which permits unrestricted use, distribution, and reproduction in any medium, provided the original work is properly cited.

\begin{abstract}
The water accumulated in the rutted road sections poses a threat to the safety of vehicles. Water-filled ruts will cause partial or complete loss of the friction between tires and the road surface, leading to driving safety hazards such as hydroplaning and sliding. At present, the maximum water depth of left and right ruts is mostly adopted to analyze the safety of water-filled ruts, ignoring the uneven change of ruts in the driving direction and the cross-section direction, which cannot fully reflect the actual impact of asymmetric or uneven longitudinal ruts on the vehicle. In order to explore the impact of water-filled ruts on driving safety, a threedimensional (3D) tire-road finite element model is established in this paper to calculate the adhesion coefficient between the tire and the road surface. Moreover, a model of the 3D water-filled rut-adhesion coefficient vehicle is established and simulated by the dynamics software CarSim. In addition, the influence of the water depth difference between the left and right ruts on the driving safety is quantitatively analyzed, and a safety prediction model for the water-filled rut is established. The results of the case study show that (1) the length of dangerous road sections based on vehicle skidding is longer than that based on hydroplaning, and the length of dangerous road sections based on hydroplaning is underestimated by $9.4 \%-100 \%$; (2) as the vehicle speed drops from $120 \mathrm{~km} / \mathrm{h}$ to $80 \mathrm{~km} / \mathrm{h}$, the length of dangerous road sections obtained based on vehicle sliding analysis is reduced by $93.8 \%$. Therefore, in order to ensure driving safety, the speed limit is controlled within $80 \mathrm{~km} / \mathrm{h}$ to ensure that the vehicle will not skid. The proposed method provides a good foundation for the vehicles to actively respond to the situation of the water-filled road section.
\end{abstract}

\section{Introduction}

The water accumulated in the rutted sections of roads poses a threat to the safety of vehicles. Water-filled ruts will cause part or all of the friction between tires and the road surface to be lost, resulting in driving safety hazards such as hydroplaning and skidding [1-3], as shown in Figure 1(a). One of the serious hazards is the imbalance of the vehicle caused by the different water depths in the ruts of the left and right wheel paths (as shown in Figure 1(b)), which will cause asymmetric lateral forces and finally the lateral offset of the vehicle. In addition, in the longitudinal direction, the rut will vary due to different loads and structures, as shown in Figure 1(c). Thus, in rainy days, the driver may still keep the high speed even on the road section with large longitudinal variability of the rut because the road conditions cannot be seen clear. The abovementioned asymmetrical lateral force and the reduced adhesion coefficient between the tire and the road affect the driver's ability to keep safe control over steering wheel, brake, acceleration, and other driving problems [6].

At present, the maximum water depth of left and right ruts is mostly adopted to analyze the safety of water-filled ruts, as shown in Figure 1(d), ignoring the uneven change of ruts in the driving direction and cross-section direction (Figure 1(c)). This does not fully reflect the actual impact of asymmetric or uneven longitudinal ruts on the vehicle and meanwhile simplifies the safety risk analysis, resulting in 


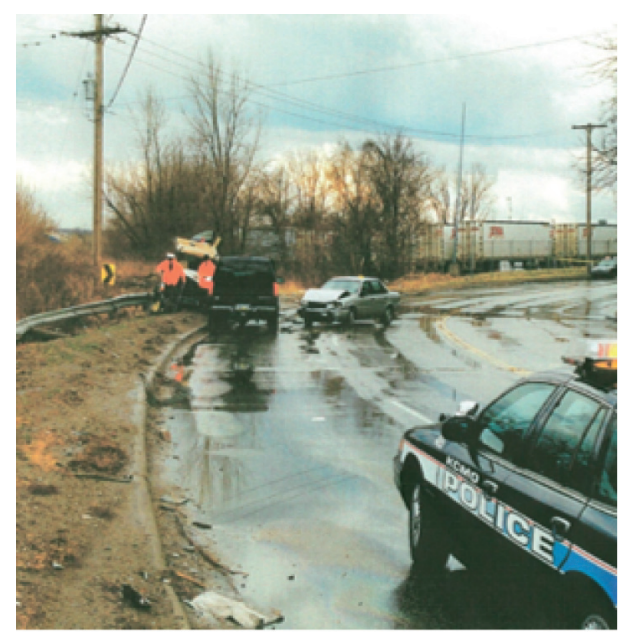

(a)

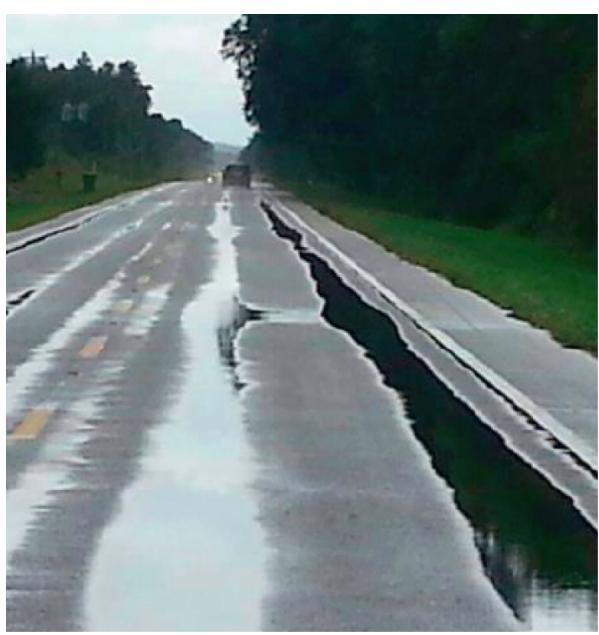

(b)

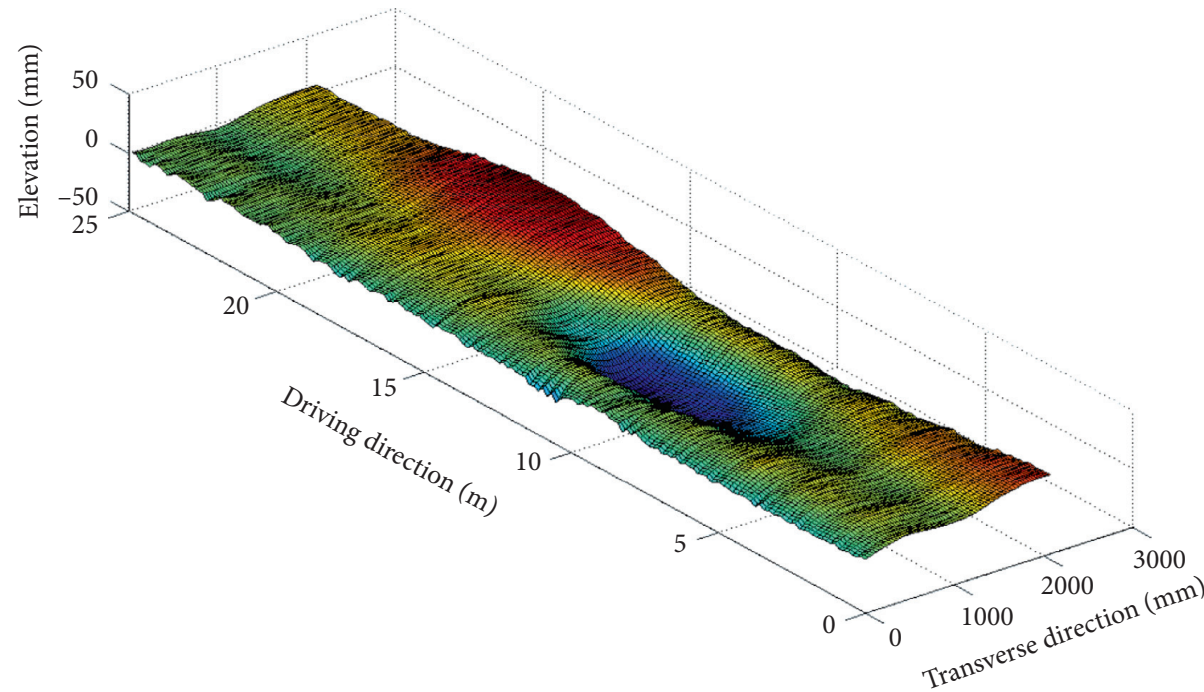

(c)

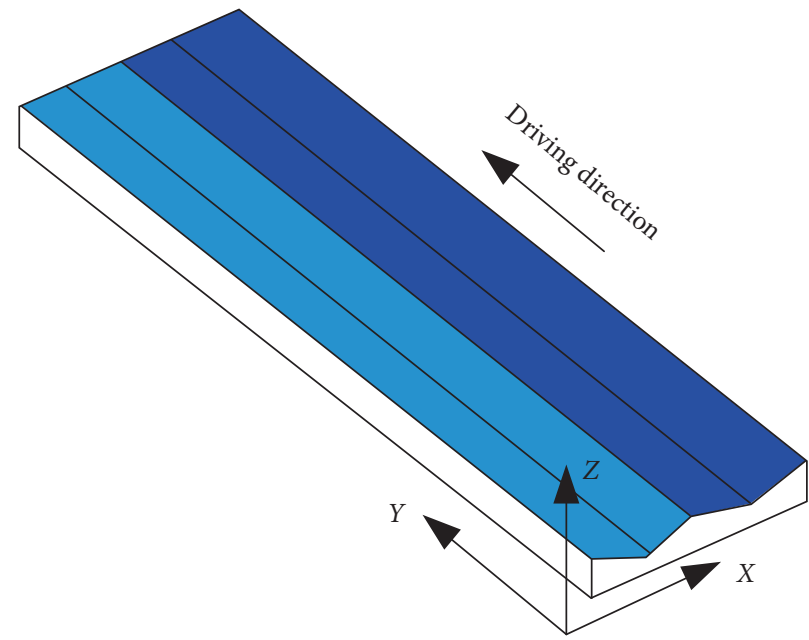

(d)

Figure 1: Uneven water-filled rut and existing water-filled rut depth model. (a) A traffic accident caused by water-filled ruts. (b) Asymmetric water-filled rut in the horizontal direction (FDOT [4]). (c) An uneven rut in both horizontal and longitudinal directions [5]. (d) The existing simplified rut depth model based on the maximum water depth of left and right ruts. 
misjudgment of the safety risks, misjudgment of the rut maintenance timing, and inappropriate allocation of maintenance funds.

The previous safety analyses of water-filled ruts usually investigate the state of a single wheel. If one of the four wheels has hydroplaning, the vehicle is considered to be in a very dangerous state. In fact, such analyses are relatively simple and one-sided. The vehicle is a whole with multiple degrees of freedom, so its dangerous state depends on the overall motion performance of the vehicle. After the vehicle slips, its driving state is determined by the tire that has hydroplaning.

To better understand the rut safety problem, different safety analysis methods regarding the water-filled rut are studied. Fwa et al. [7] developed an analytical procedure for the rut depth intervention level based on the concept of the skid resistance intervention level. This method relies on the already known standardized skid resistance threshold and the skid resistance-vehicle speed curves for different waterfilled rut depths through the established contact model between tires and water by using the finite element method. Luo [8] used IMU and $1 \mathrm{~mm} 3 \mathrm{D}$ laser data to evaluate hydroplaning risk based on the Gallaway WFD model. This model was also used by the Federal Department of Transportation to predict hydroplaning potential. The above models perform hydroplaning and safety analysis based on the maximum depth of the left and right ruts. They have the advantages of simple geometric definition and convenient measurement so that it is easy to find the critical trigger point. They provide a more direct basis for road condition assessment and maintenance decision analysis and have good applicability.

In these methods, however, the maximum depth of the left and right ruts used for safety analysis is an unreliable index. It can be seen that two profiles with the same maximum rut depth may have different rut profiles. Full-lane coverage rut profile's information could be more meaningful than the singular parameter of maximum hypothetical water depth valid for a single point in the cross section. After all, the vehicle tires have a specific width, and a vehicle has four wheels, and one of the tires has a complete hydroplane without the vehicle's driving stability being necessarily lost [1]. In addition, these methods do not consider the danger of skidding and offset under the imbalanced left and right friction coefficients caused by the difference of water-filled rut depth. And, these methods focused more on the complete hydroplaning, but failed to take partial hydroplaning into consideration. Under partial hydroplaning, differential rut depth (or friction) between the right and left wheel paths could result in imbalanced lateral forces and further lateral stability issues such as vehicle skidding, according to the early studies of Burns [3]. Some other researchers like Xu et al. [9] and Han et al. [10] used Automatic Dynamic Analysis of Mechanical Systems (ADAMS) to simulate differential friction skidding situations, but the roadway surface (friction) they used are not real-world data. It cannot consider the rutted and unrutted sections, so the synthetic frictions are used to represent half cross-section pavements, which cannot represent the real road full-lane pavement condition.
Thus, there is a need to develop a method that can be used to adequately evaluate and describe the behavior of a vehicle on the water-filled rut. With the advance of $3 \mathrm{D}$ technology, it provided a high-resolution, full-lane width coverage $3 \mathrm{D}$ point cloud data, and it is feasible to extract the rutting depths in every $1 \mathrm{~mm}$. Thus, the objective of this paper is to establish a method with $3 \mathrm{D}$ point cloud data to find the vehicle response on the real-world water-filled rut instead of traditionally used the maximum rut depth of the left and right wheel path for a single point in the cross section on travel safety analysis. To be specific, this paper mainly tries to show the difference between the proposed method by using the full-lane rut depth and the roughly maximum rut depth.

\section{Theoretical Analysis of Critical Rut Depth Determination}

2.1. Analysis of Complete Hydroplaning of the Vehicle. Hydroplaning refers to the separation of the tires of a moving vehicle from the road surface by the water on it. In this case, the driver is incapable of taking control over the steering or braking of the vehicle. When the vehicle runs on a road covered by a water film, the rolling tires will squeeze the water film to generate hydrodynamic pressure that causes the tires to float. Hydroplaning occurs when the hydrodynamic buoyancy acting on the tires is equal to the weight plus the vertical load on them $[6,11,12]$. At this point, the reduction in the contact area between the tires and the road results in a decrease in the adhesion coefficient so that the driver is unable to control the forward direction of the vehicle, and the stability of the vehicle will decrease.

2.2. Analysis of Vehicle Sliding. When the left and right wheels of the vehicle are running in the grooves of the left and right ruts, respectively, the following two working conditions will occur:

(1) When the water depths of the left and right ruts are equal $\left(\mathrm{WD}_{L}=\mathrm{WD}_{R}\right)$, the adhesion coefficients between the left and right tires and the road surface will drop to the same degree, which will lead to a longer braking distance, but not the skidding of the vehicle

(2) When the water depths of the left and right ruts are not equal $\left(\mathrm{WD}_{L} \neq \mathrm{WD}_{R}\right)$, the adhesion coefficients between the left and right tires and the road surface are different, so the vehicle will skid

In practice, due to the effect of the cross slope of the road, the forces on the left and right wheel paths are not equal, resulting in unequal depths of the left and right ruts. The specific mechanism of the impact of such asymmetrical ruts on the vehicle is shown in Figure 2. When the vehicle encounters water, the adhesion coefficient between the left front wheel and the road surface is reduced, which further decreases the friction between the left front wheel and the rut surface. In a unit time, the left front wheel decelerates relative to the right front wheel, causing the vehicle to deflect to the left. At the same time, it will cause a large slip angle $\beta$ 


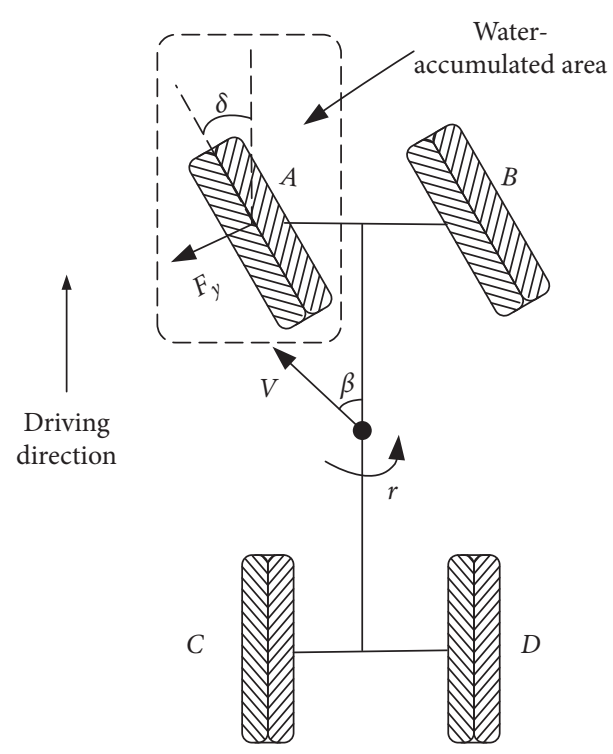

FIGURE 2: Schematic diagram of vehicle sliding caused by the water accumulated in the rut.

of vehicle centroid, resulting in vehicle oversteer and even loss of control.

According to the different out-of-control states mentioned above, this paper proposes an improved method for determining the water-filled rut depth. The flowchart is shown in Figure 3. The determination of the critical rut depth needs to be considered in two separate cases: symmetric rut and asymmetric rut. The previous threshold determination method is to study the critical depth of the symmetrical rut, so the research object is the critical point of the maximum rut depth for a driving danger. In this case, the analysis of complete hydroplaning and actual braking distance of the vehicle can be achieved based on a single rut depth. Nevertheless, it can be seen from the above analysis of the rut profile that the cross-sectional shapes of ruts may be different even in case of identical maximum rut depths, resulting in the asymmetrical rut. Such asymmetrical ruts will cause the vehicle to slide, while running in a straight line and braking, and even a more dangerous rotational motion. In the process of skidding, the water depth of the entire cross-sectional area as well as the rut width will also impact the lateral offset, lateral acceleration, heading angle, and other indicators of the vehicle. Vehicle sliding induced by the asymmetric rut can also occur in the case of partial hydroplaning. In other words, even if the water depth of the rut is too small to cause complete hydroplaning, a large difference in the depths of the left and right ruts will lead to unsafe driving as well. Therefore, it is inadequate to evaluate the safety of the water-filled rut through the dangerous state of complete hydroplaning. This paper takes the evaluation of vehicle sliding with partial hydroplaning as an example to analyze the driving safety of the water rut. The evaluation methods under other conditions are consistent with the skidding evaluation method. The purpose of this paper is to enrich the current approaches for calculating the critical rut depth. A case study is carried out to compare the lengths of dangerous road sections based on complete hydroplaning and vehicle sliding.

\section{Establishment of the Research Model and Prediction Model}

The purpose of this section is to use the high-resolution $3 \mathrm{D}$ pavement data to establish a grid distribution model of the adhesion coefficient of the water-filled rut, so as to analyze the safety risks induced by water-filled ruts under real road conditions. The safety analysis model of the water-filled rut is established in the following three steps: (1) division of the water accumulation area in the rut and calculation of water depth, (2) computation of the adhesion coefficient based on a 3D tire-road finite element model, and (3) establishment of the $3 \mathrm{D}$ water-filled rut-adhesion coefficient vehicle model and safety analysis. First, the water accumulation area is divided, and the accumulated water depth in the grid after the division is computed based on the calculated rut water depth. Subsequently, the regression equation of the vehicle adhesion coefficient is established after considering the depth of the tire pattern, the speed of the vehicle, and the water depth. Finally, a vehicle-rut multi-degree-of-freedom model is established to analyze the safety of the vehicle when the water depths of the left and right ruts are different (Figure 4).

3.1. Division of the Water Accumulation Area in the Rut and Water Depth Calculation. This paper will take the grid of tire and road contact area as an example to introduce the method of dividing the water area in the rut, as shown in Figure 5(a). Each grid consists of the area enclosed by the tire width and the tire-road contact length. At the same time, it is assumed that each grid has only one water depth, that is, the maximum water depth in the current grid is used to represent the water depth of the entire grid. The water depths are represented by different colors, and the color of each grid is uniform. The darker the grid color, the greater the water depth. The selection of the maximum water depth is shown in Figure 5(b), where the red and green points both indicate the maximum water depth in each grid. The water depth corresponding to the red dot is the maximum water depth of the commonly used maximum depth method. In addition, while dividing the cross-section grid, the maximum water depth of the rut is taken as the center to extend half the tire width to both sides so that the maximum water depth is included in the grid. Figure 5(c) shows the grid distribution of the water area under the 3D perspective.

Here, taking the grid of the contact area between the tire and the road surface as an example, the method of dividing the rut water area is introduced. The water area is represented by the area enclosed by the tire width and the tireroad contact length, as shown in Figure 5(a). It is assumed that there is only one water depth in each grid, so the maximum water depth in the grid is used to represent the water depth of the entire grid. In Figure 5(a), the water depths are represented by different colors, and the color of each grid is uniform; the darker the grid color, the greater the water depth. The selection of the maximum water depth is shown in Figure 5(b). The red and green points in the figure both indicate the maximum water depth in the grid. The 


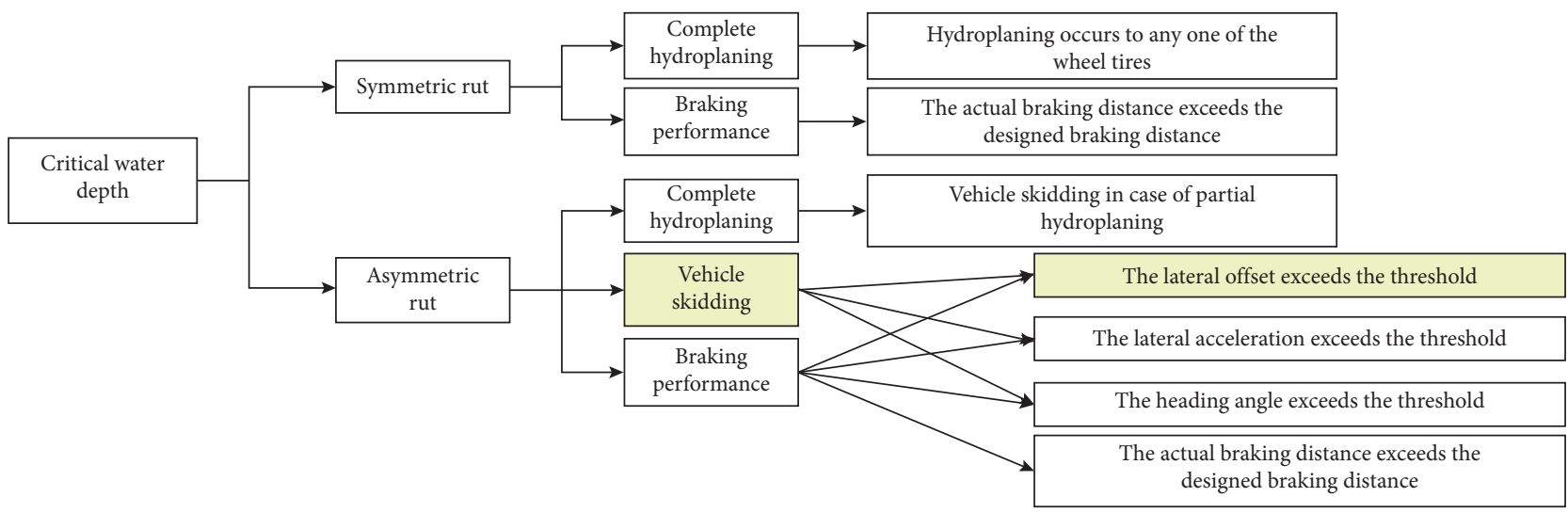

FIGURE 3: Impact of 3-dimensional ruts on driving safety.

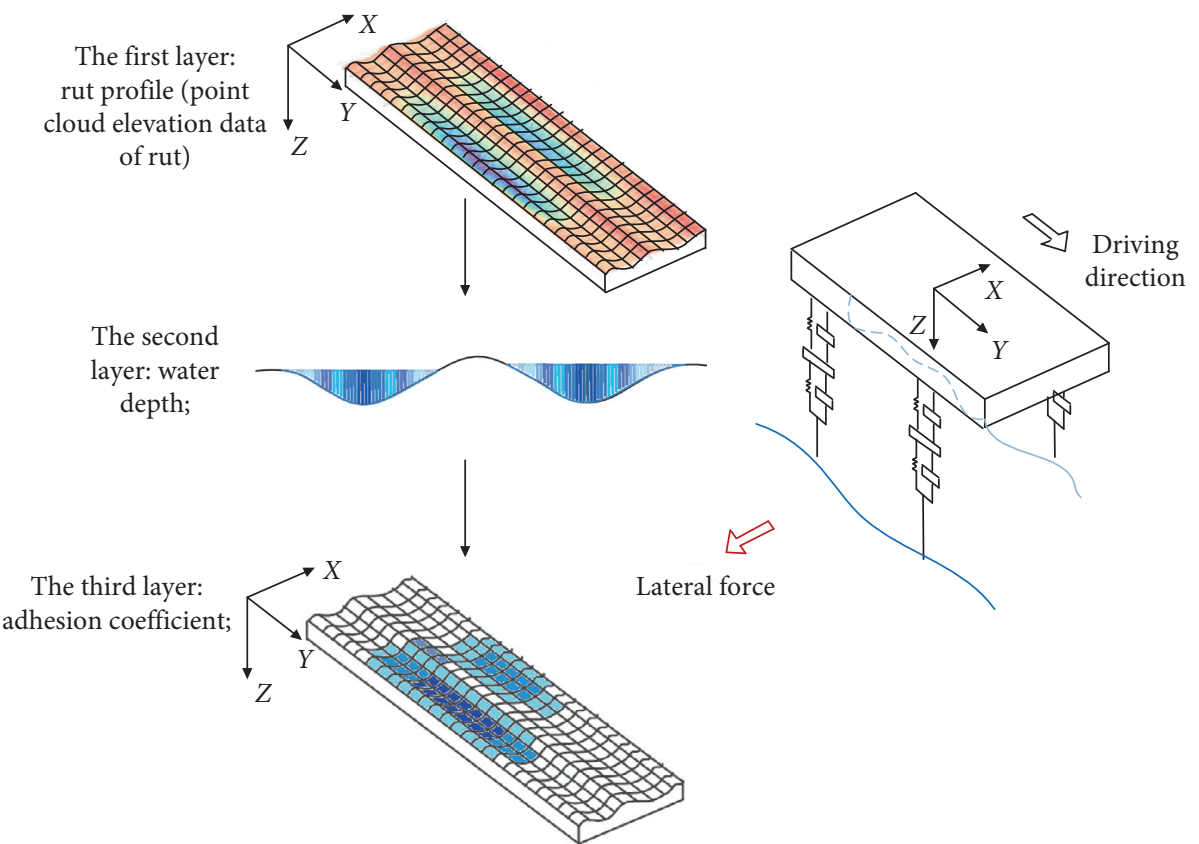

Figure 4: Schematic diagram of impact of the water-filled rut on vehicle safety.

water depth corresponding to the red dot is the maximum water depth which is compared with the commonly used maximum depth method. Moreover, when the cross-section grid is divided, the maximum water depth is taken as the center to extend half the tire width to both sides, in which way the maximum water depth is included in the grid.
Figure 5(c) shows the grid distribution of the water area from a $3 \mathrm{D}$ perspective.

The grid-based water depth is the height difference between the horizontal water line and the maximum depth in each grid of the rut profile. Therefore, for a rut profile, the water depth of each grid is calculated by the following formula:

$$
\mathrm{WD}_{\text {gridi }}= \begin{cases}\mathrm{WD}_{\text {lgridi }}=Z_{1}-Z_{\text {gridi }}, & x_{1}<\text { gridi }<x_{i}, \\ \mathrm{WD}_{\text {rgridi }}=Z_{\text {gridnumber }}-Z_{\text {grid }(i+1)}, & x_{i+1}<\text { gridi }<x_{\text {gridnumber }},\end{cases}
$$

where $\mathrm{WD}_{\text {gridi }}$ is the water depth of the $i$ th grid, $\mathrm{WD}_{\text {lgridi }}$ and $\mathrm{WD}_{\text {rgridi }}$ are the water depths of the $i$ th grid of the left and right wheel paths, and $Z_{\text {gridi }}$ is the maximum depth of the $i$ th grid in a rut profile.
3.2. Calculation of the Adhesion Coefficient of the WaterAccumulated Grid in the Model. After the water area of the rut is divided, it is necessary to determine the adhesion coefficient of each water grid. Approaches for calculating the 


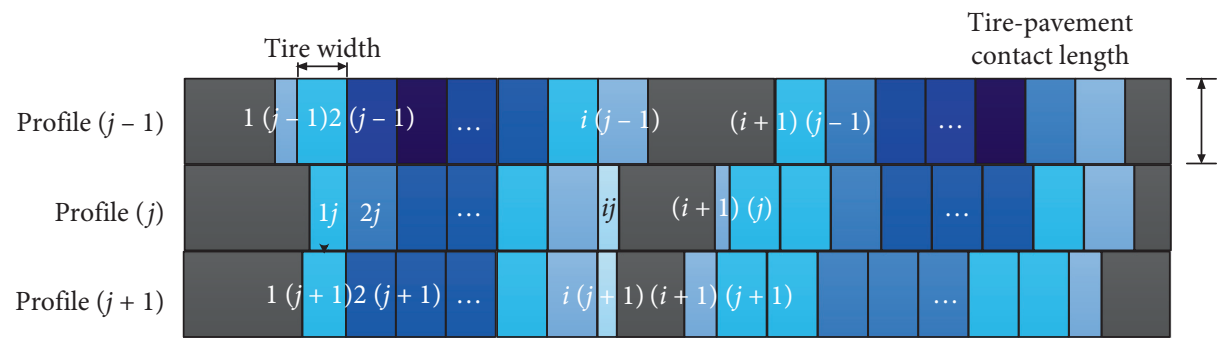

(a)

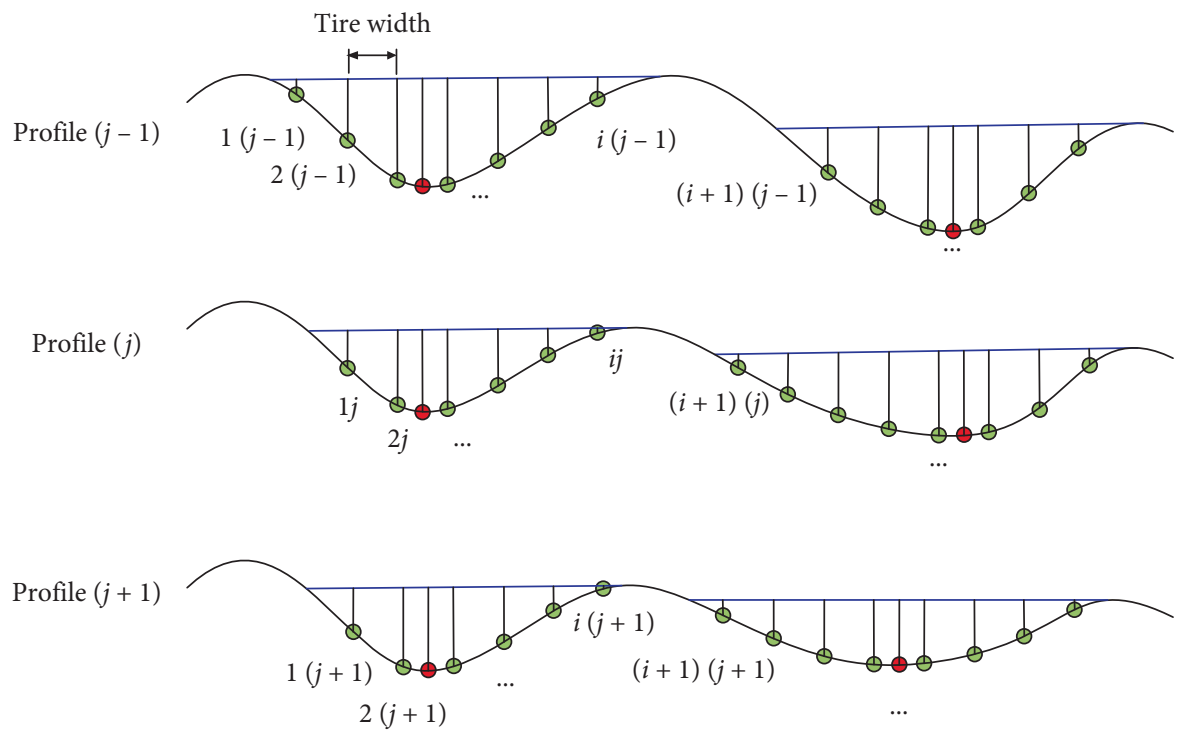

(b)

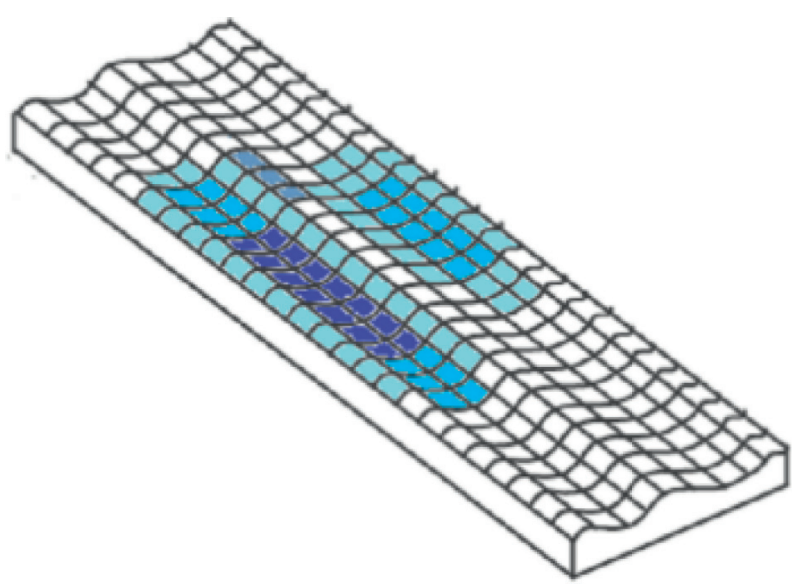

(c)

FIgURE 5: Grid-based water depth distribution. (a) Division of the water accumulation area based on the tire-road contact area. (b) Adjacent rut profile with maximum water depth in each grid (transverse direction). (c) Grid distribution of the water area under the 3D perspective.

adhesion coefficient include empirical methods and mechanical methods. This paper uses the mechanics method shown in Figure 6 to establish a 3D tire-road finite element model and obtains the regression equation of the adhesion coefficient between the tire and the water-accumulated road surface. With detailed information of grid-based water depth and adhesion coefficient distribution, it is possible to analyze the impact of the horizontally asymmetric and longitudinally uneven water-filled rut on driving safety.
The adhesion coefficient in each water-accumulated grid is calculated by the $3 \mathrm{D}$ tire-road finite element model. This model takes into account the water depth, vehicle speed, and tire pattern depth and uses tire-water hydrodynamics [13-15] for simulation. In this paper, FLUENT is utilized to simulate the $3 \mathrm{D}$ tire-road finite element model. This software is often applied to simulate fluid flow, heat transfer, and chemical reactions. 


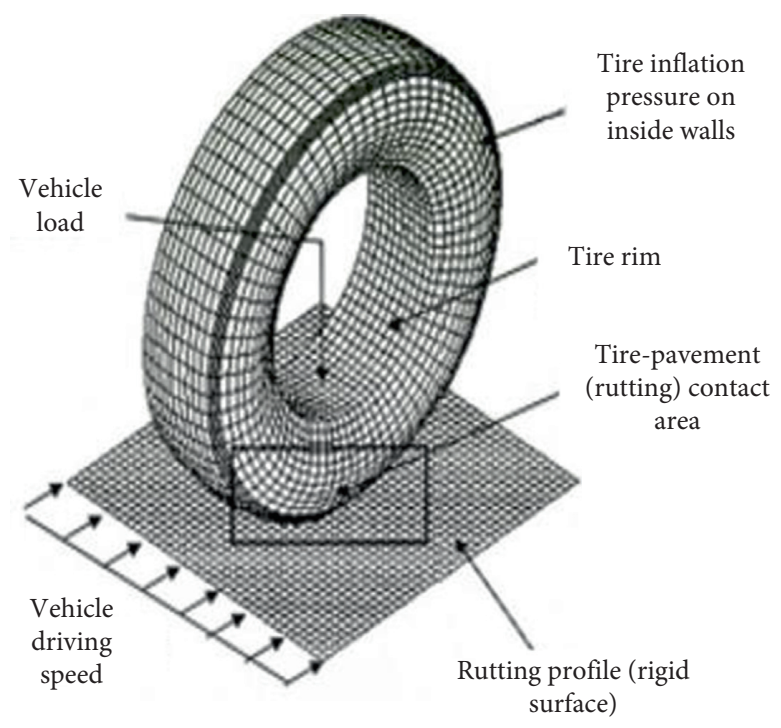

(a)

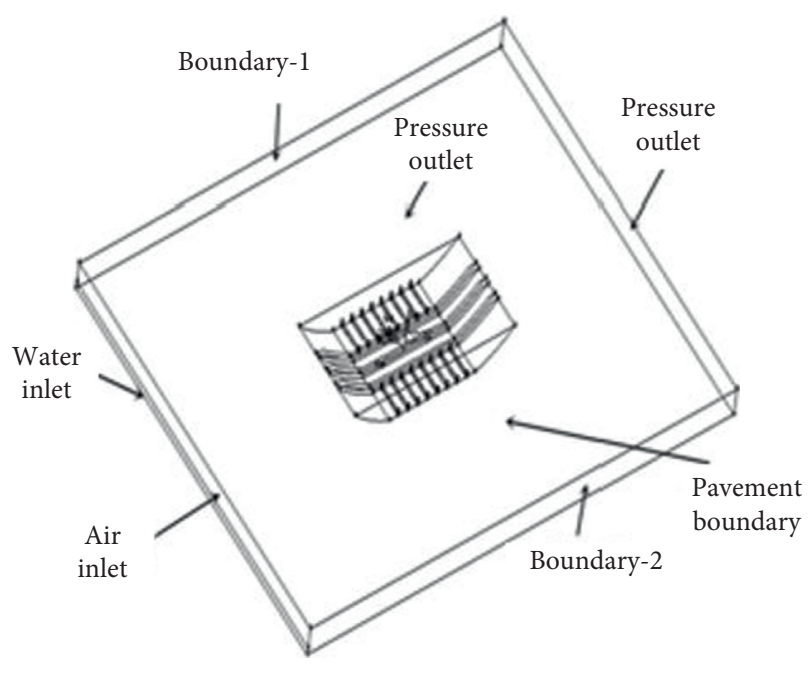

(b)

Figure 6: The 3D tire-road finite element model and the setting of model boundary conditions. (a) Tire hydroplaning FEM. (b) Fluid model.

Regression formula between the water depth and the adhesion coefficient

Tire type 225/60 R18

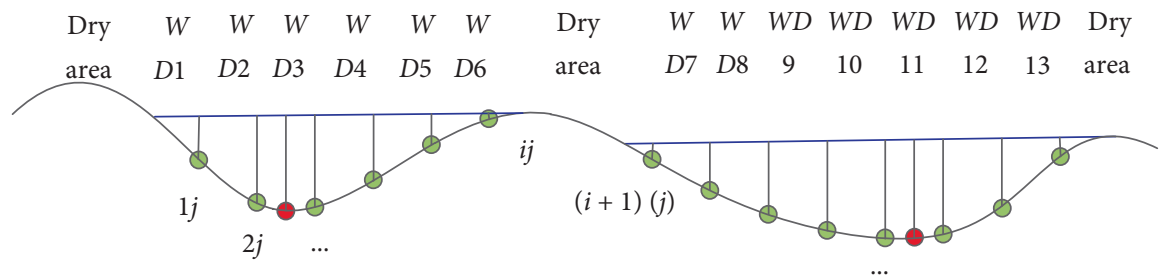

$$
\begin{aligned}
& f-0.1921=-0.01106(W D-5) \mathrm{V}=80 \mathrm{~km} / \mathrm{h} \\
& f-0.0800=-0.00574(W D-5) \mathrm{V}=100 \mathrm{~km} / \mathrm{h} \\
& f-0.0502=-0.00398(W D-5) \mathrm{V}=120 \mathrm{~km} / \mathrm{h}
\end{aligned}
$$
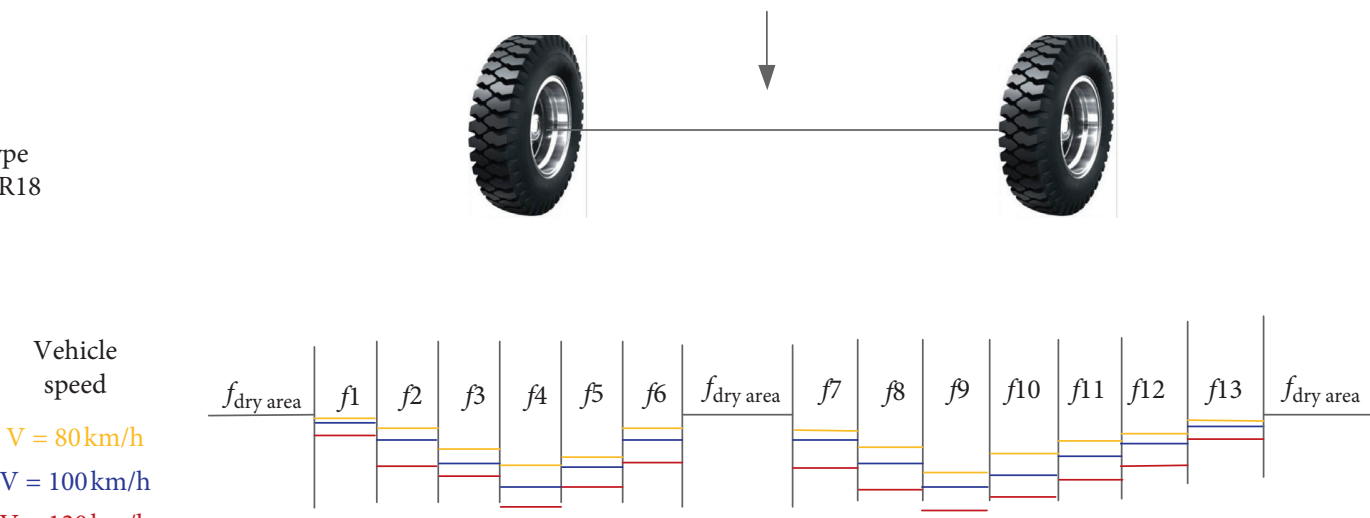

Figure 7: Conversion of water depth into adhesion coefficient.

Based on the water depth, the regression equation of the adhesion coefficient between the tire and the water-accumulated road surface at different speeds can be calculated (see formula $(2-4)$ ):

$$
\begin{gathered}
f-0.1921=-0.01106(\mathrm{WD}-5), \quad V=80 \mathrm{~km} / \mathrm{h}, \\
f-0.0800=-0.00574(\mathrm{WD}-5), V=100 \mathrm{~km} / \mathrm{h},
\end{gathered}
$$




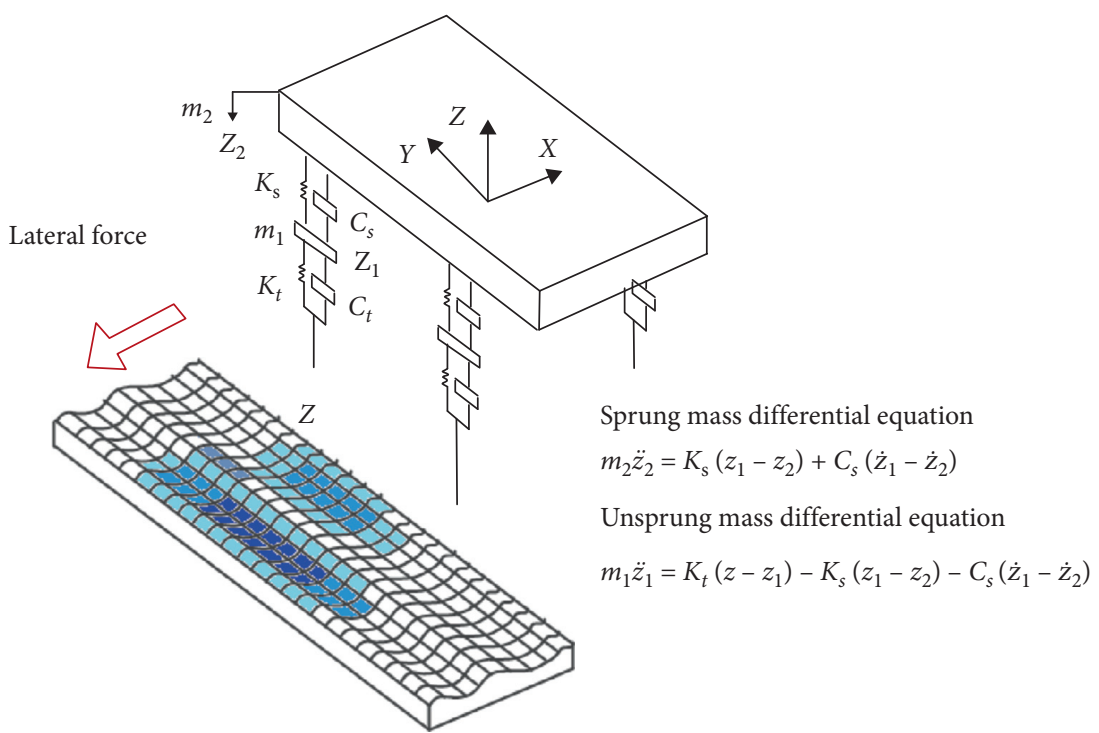

FIgURE 8: 3D differential equation model of the vehicle pavement with multidegree of freedom.

$$
f-0.0502=-0.00398(\mathrm{WD}-5), \quad V=120 \mathrm{~km} / \mathrm{h} .
$$

In the above formulae, $f$ is the adhesion coefficient between the tire and the water-accumulated road surface, $V$ is the vehicle speed $(\mathrm{km} / \mathrm{h})$, and the adhesion coefficient in the dry area is 0.5 [15]. During the model simulation, it is found that when the water depth exceeds $5 \mathrm{~mm}$, it has a good linear relationship with the adhesion coefficient between the tire and the water-accumulated road surface; when the water depth is below $5 \mathrm{~mm}$, however, this linear relationship no longer exists. Therefore, in the following analysis, the water depth of the rut is greater than $5 \mathrm{~mm}$.

Taking Section $(j)$ as an example, Figure 7 illustrates the conversion of the water depth in each grid of the rut profile into the adhesion coefficient. It can be seen that the rut water area is divided by the tire width, and the water depths $\mathrm{WD}_{1}, \mathrm{WD}_{2}, \ldots, \mathrm{WD}_{13}$ are calculated. Through the regression formula between the water depth and the adhesion coefficient, for the selected tire 225/60 R18, its adhesion coefficients $f_{1}, f_{2}, \ldots f_{13}$ at different speeds can be calculated. It can also be seen that the adhesion coefficient of the grid with identical water depth varies under different vehicle speeds. The blue and red dashes in the figure represent the adhesion coefficients of the grid at vehicle speeds of $100 \mathrm{~km} / \mathrm{h}$ and $120 \mathrm{~km} / \mathrm{h}$, respectively. The higher the vehicle speed, the smaller the adhesion coefficient.

\subsection{Establishment of 3D Water-Accumulated Rut-Adhesion} Coefficient-Vehicle Model and Safety Analysis. The rut water depth and the 3D tire-road finite element model are used to calculate the adhesion coefficient between the tire and the water-accumulated road surface. Based on the dynamic differential equation theory and the vehicle model (fourwheel model) [16-18], a 3D water-filled rut-adhesion coefficient-vehicle model with 27 degrees of freedom is stabled and used for driving safety analysis. As shown in Figure 8, the left front wheel is taken as an example to describe the dynamic differential equation of the vehicle motion. This function takes into account the sprung mass $\left(m_{2}\right)$, the unsprung mass $\left(m_{1}\right)$, the $K_{\mathrm{s}}\left(K_{\mathrm{t}}\right)$ and $C_{\mathrm{s}}\left(C_{\mathrm{t}}\right)$ performance $(\mathrm{KC}$ characteristics) of the suspension and tires, and the $1 / 4$ vertical elevation $(Z)$ of a continuous road [19]. Combined with the adhesion coefficient of the grid, the model is capable of analyzing the vehicle's driving safety during lateral sliding, for example, whether the lateral offset reaches the threshold, and also simulating different driving conditions (such as changing the vehicle speed and driving operations).

CarSim, a piece of common vehicle dynamics analysis and simulation software, is used to establish a $3 \mathrm{D}$ vehicle-road interaction model and analyze the lateral offset of the vehicle. It can import road information (including road alignment, vertical elevation of cross section, and adhesion coefficient) and vehicle parameter information through different modules. In the car simulator, the mathematical model of the vehicle four-wheel model has over 110 ordinary differential equations and 250 state variables that can fully define the state of the system [16-18]. In addition, many researchers, including Cao et al. [20], Guo [14], Zhang [15], and Pilgrim [21], also use CarSim to simulate and analyze the safety problems arising from the reduced adhesion coefficient between the road surface and the vehicle.

The simulation test consists of three steps. The first step is to build a vehicle model in CarSim. The vehicle module in CarSim contains various types of vehicles which can be selected according to research needs. The second step is to establish a road surface model, into which the road surface point cloud data are input through the geometry module. The adhesion coefficient of each road surface grid is input to CarSim via the road friction map module. The final step is to output the variation curve of the lateral offset with driving time to analyze the impact of the water-filled rut on driving safety.

3.4. Evaluation Indices of Safety of the Water-Filled Rut. Figure 9 shows the rut-vehicle model under practical road conditions. The road model is a two-way two-lane road, and 


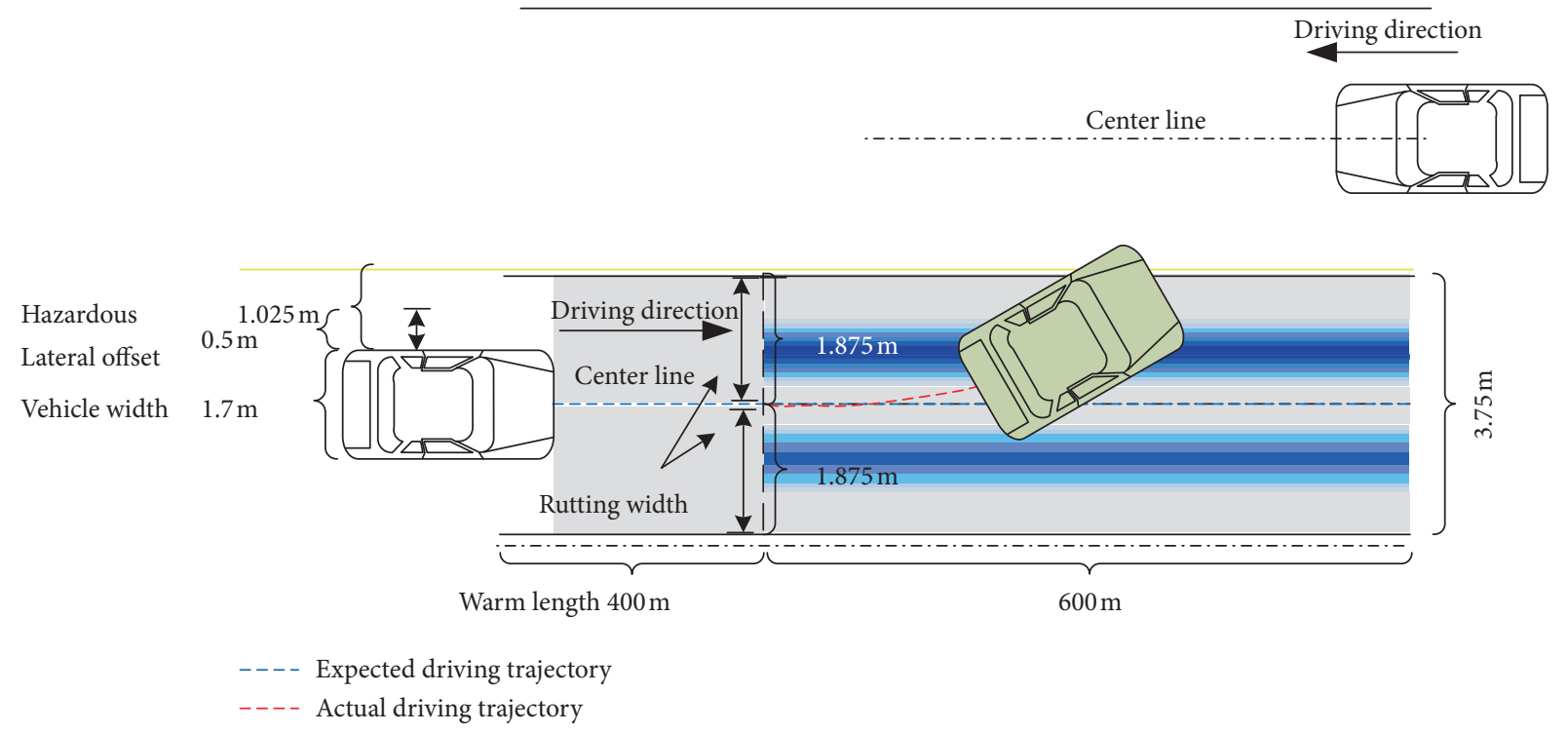

Figure 9: Hazardous lateral offset during vehicle skidding.

the lower lane is accumulated with some water. There is more water in the left rut than in the right rut (the darker the blue, the larger the water depth). The curve in the figure is the actual sideslip trajectory of the vehicle, and the vehicle slides towards the direction where there is more water [22]. C. J. Baker believes that the vehicle should be determined to have sliding risks once its lateral offset exceeds $0.5 \mathrm{~m}$. This method has been widely applied in practical engineering [23-26]. Nevertheless, this indicator fails to describe the state of the road surface and reflect the influence of rut water depth on the lateral offset. Indeed, whether the lateral offset is dangerous needs to be comprehensively determined in conjunction with the slip time.

The research object of this paper is rut. When the vehicle slips out of the rut's water area, the water depth will change dramatically. Assuming that the vehicle tire is running in the center of the rut, the vehicle's slipping out of the water area is defined as the lateral offset exceeding half of the rut width, and the time for the vehicle to skid out of the water area is recorded as slip time, denoted by $T$. When the slip time $T$ is longer than the driver's judgment and reaction time for a complicated situation, the vehicle is immediately in danger.

3.5. Establishment of the Safety Prediction Model of the WaterFilled Rut. In order to establish the correlation between the water-filled rut index and the safety evaluation index, the rut detection data of the Xi'an-Shangzhou Expressway section in Shaanxi Province are preprocessed, and the influence of the water depth difference between left and right ruts (hereinafter referred to as water depth difference) on the total lateral offset is obtained and applied to predict and analyze the safety of the water-filled rut.

The water depth difference is changed to observe its impact on the lateral slip time. The positions of the maximum water depths of the ruts are the same, so are the ruts' widths. At a vehicle speed of $100 \mathrm{~km} / \mathrm{h}$, the water depth of the right rut remains unchanged, and the water depth of the left is altered at intervals of $1 \mathrm{~mm}$ from $7 \mathrm{~mm}$ to $15 \mathrm{~mm}$, so the water depth difference varies between $2 \mathrm{~mm}$ and $10 \mathrm{~mm}$. The left and right rut widths are $1249 \mathrm{~mm}$ and $1290 \mathrm{~mm}$, respectively. The lateral slip time is analyzed according to the minimum width, so the risk threshold of the lateral offset is $0.6 \mathrm{~m}$.

It can be seen from Figure 10 that when the maximum rut depths are equal, the increase in the left rut depth will lead to a reduction in water depth difference, but an increase in the slip time. The greater the water depth difference, the easier it is to reach the slip risk threshold. Specifically, when the water depth difference is $6 \mathrm{~mm}$, the slip time is $5.2 \mathrm{~s}$; when the difference is $7 \mathrm{~mm}$, the slip time is $4.8 \mathrm{~s}$, which is close to the driver's reaction time to complex situations of $5 \mathrm{~s}$ $[27,28]$. It is, therefore, preliminarily determined that the critical value of the water depth difference is $6.5 \mathrm{~mm}$ when the vehicle speed is $100 \mathrm{~km} / \mathrm{h}$.

In order to quantitatively explore the influence of the water depth difference on the slip time, the above relationship is further analyzed through multiple rut profiles, that is, 7 experimental groups with a total of 42 pairs of rut profiles are simulated, as shown in Table 1. Here, the water depth difference between the right and left ruts ranges within $4 \mathrm{~mm}$ and $10 \mathrm{~mm}$. In this case, the maximum rut water depth is $17 \mathrm{~mm}$ and the minimum is $5 \mathrm{~mm}$, which, respectively, meet the conditions for partial hydroplaning and the basic requirements for the linear regression formula of the adhesion coefficient.

Figure 11 shows the results of the above experiment. From the correlation analysis between the water depth difference and the lateral slip time, it can be seen that the water depth difference shows a good linear relationship with the slip time obtained by simulation, and the regression coefficient is 0.9415 . Draw a horizontal line with the critical value of dangerous time $5 \mathrm{~s}$. This time is the driver's reaction time to complex judgments and understandings. Intersected with the linear regression formula, the dangerous left and 


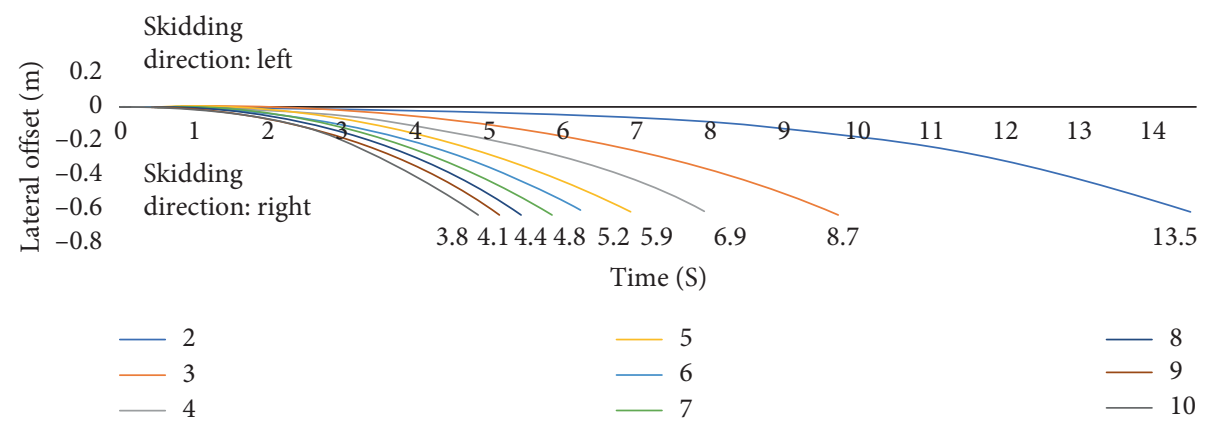

Figure 10: Impact of the water depth difference on the lateral slip time.

TABLE 1: Settings of left and right rut water depths.

\begin{tabular}{lcc}
$\begin{array}{l}\text { Experimental } \\
\text { group }\end{array}$ & $\begin{array}{c}\text { Water depth difference/ } \\
\mathrm{mm}\end{array}$ & $\begin{array}{c}\text { The water depth corresponding to the left wheels and the water depth corresponding to the } \\
\text { right wheels/mm-mm }\end{array}$ \\
\hline 1 & 10 & $17-7,16-6$, and $15-5$ \\
2 & 9 & $17-8,16-7,15-6$, and $14-5$ \\
3 & 8 & $17-9,16-8,15-7,14-6$, and $13-5$ \\
4 & 7 & $17-10,16-9,15-8,14-7,13-6$, and $12-5$ \\
5 & 6 & $17-11,16-10,15-9,14-8,13-7,12-6$, and $11-5$ \\
6 & 5 & $17-12,16-11,15-10,14-9,13-8,12-7,11-6$, and $10-5$ \\
7 & 4 & $17-13,16-12,15-11,14-10,13-9,12-8,11-7,10-6$, and $9-5$ \\
\hline
\end{tabular}

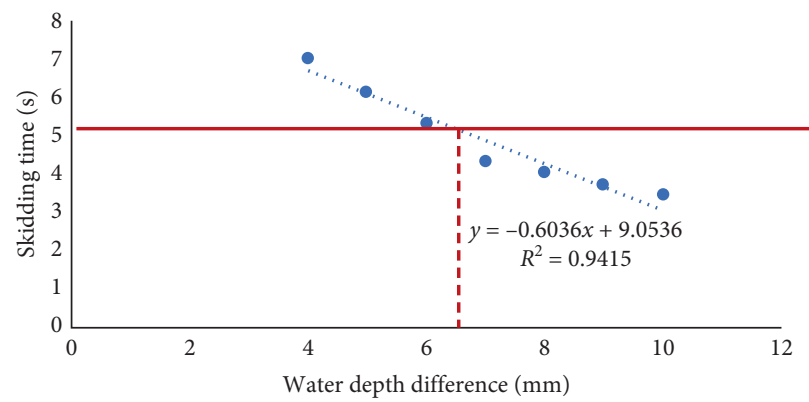

Figure 11: Correlation between vehicle slip time and water depth difference.

TABLE 2: Comparison of lengths of dangerous road sections obtained by complete hydroplaning- and sliding-based methods.

\begin{tabular}{lcccc}
\hline $\begin{array}{l}\text { Vehicle } \\
\text { speed } \\
(\mathrm{km} / \mathrm{h})\end{array}$ & $\begin{array}{c}\text { Length of dangerous road section }(\mathrm{m}) \\
\text { Obtained by } \\
\text { hydroplaning-based } \\
\text { method }\end{array}$ & $\begin{array}{c}\text { Obtained by } \\
\text { sliding-based } \\
\text { method }\end{array}$ & $\begin{array}{c}\text { Comparison of assessed results (hydroplaning- } \\
\text { based method-sliding-based method)/Sliding- } \\
\text { based method }\end{array}$ & $\begin{array}{c}\text { Increase in the length of } \\
\text { dangerous road sections by } \\
\text { sliding-based method (\%) }\end{array}$ \\
\hline 80 & 0 & 10 & $100 \%$ lower by hydroplaning-based method & 60 \\
100 & 145 & 160 & $9.4 \%$ lower by hydroplaning-based method & 150 \\
120 & 154 & 256 & $41.9 \%$ lower by hydroplaning-based method & \\
\hline
\end{tabular}

right water depth difference is $6.7 \mathrm{~mm}$. This value is the water depth difference for a dangerous situation and is roughly equal to the critical value preliminarily determined above.

\section{Case Study}

Based on the established water-filled rut safety research model, the measured data of rut profiles, the spatial distribution of water depth difference in the driving direction, and the safety of the rut section can be assessed from the perspectives of time and space. Table 2 shows the lengths of dangerous road sections at different vehicle speeds calculated separately in cases of complete hydroplaning and sliding. The comparison shows that the lengths of dangerous road sections based on sliding exceed those based on hydroplaning. In other words, the sliding-based risk 


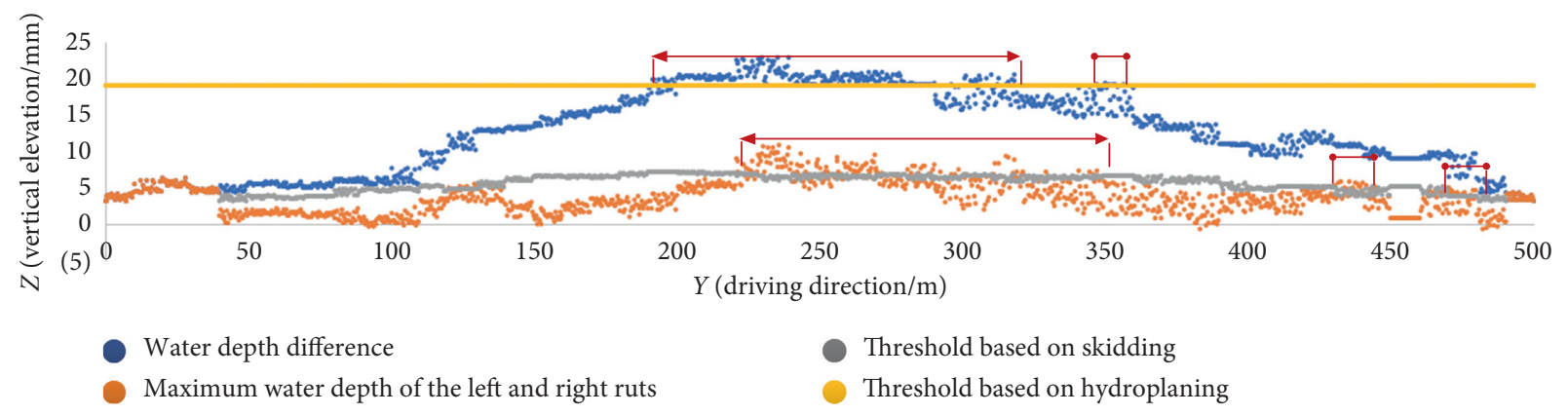

Figure 12: Safety assessment of the water-filled rut $(100 \mathrm{~km} / \mathrm{h})$.

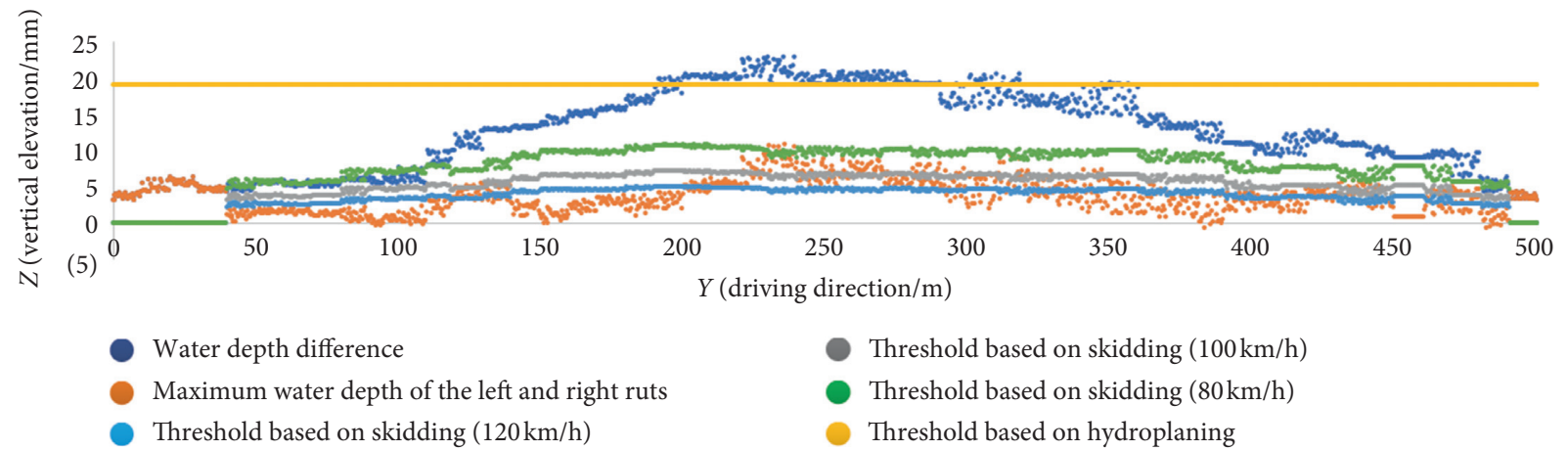

Figure 13: Safety risk assessment of the water-filled rut at different speeds (80, 100, and $120 \mathrm{~km} / \mathrm{h})$.

assessment method is more conservative than the hydroplaning-based. It can be concluded that when the rut severity and the vehicle speed are low, the hydroplaning-based risk assessment method will greatly underestimate the risk of the water-filled rut.

Figure 12 illustrates the safety assessment of the dangerous road sections caused by water-filled ruts. The areas marked by arrows are the dangerous sections. The orange point cloud data are the distribution of the maximum water depth of the left and right ruts. The blue point cloud data is the distribution of the water depth difference. The gray curve and the yellow straight line are the threshold lines based on vehicle skidding and complete hydroplaning, respectively. The vertical elevation of the rut corresponding to the hydroplaning-based threshold line is $19 \mathrm{~mm}$. When the blue point data, i.e., the maximum water depth, is greater than $19 \mathrm{~mm}$, complete hydroplaning will occur. When the orange point cloud data, that is, the water depth difference is higher than the gray curve, the vehicle will slip before the driver has time to react. The evaluation of two dangerous sections of $190 \mathrm{~m}-320 \mathrm{~m}$ and $340 \mathrm{~m}-355 \mathrm{~m}$, with a total length of about $145 \mathrm{~m}$, is obtained by the complete hydroplaning-based assessment method; three dangerous sections of $220 \mathrm{~m}-350 \mathrm{~m}, 430 \mathrm{~m}-445 \mathrm{~m}$, and $465 \mathrm{~m}-480 \mathrm{~m}$, totaling about $160 \mathrm{~m}$, are obtained by the vehicle sliding-based evaluation method. The dangerous sections evaluated by the two approaches should be superimposed to form the final dangerous sections of $190 \mathrm{~m}-355 \mathrm{~m}, 430 \mathrm{~m}-445 \mathrm{~m}$, and $465 \mathrm{~m}-480 \mathrm{~m}$, with a total length of $195 \mathrm{~m}$. For water-filled rut sections with safety risks, a more economical and effective way is to reduce the speed of vehicles in addition to
TABLE 3: Reduction in length of dangerous sections by decreased vehicle speeds.

\begin{tabular}{ccc}
\hline Year & $120 \longrightarrow 100(\mathrm{~km} / \mathrm{h})(\%)$ & $100 \longrightarrow 80(\mathrm{~km} / \mathrm{h})(\%)$ \\
\hline 2017 & 39.6 & 93.8 \\
\hline
\end{tabular}

maintenance. Thus, it is recommended to control the driving risk by lowering the vehicle speed on rutted sections under the premise of adequate capacity of the road section.

In addition to the skidding threshold line at a speed of $100 \mathrm{~km} / \mathrm{h}$, the threshold lines at $120 \mathrm{~km} / \mathrm{h}$ and $80 \mathrm{~km} / \mathrm{h}$ are added for further analysis. As shown in Figure 13, the $120 \mathrm{~km} / \mathrm{h}$ threshold line is lower than the $100 \mathrm{~km} / \mathrm{h}$ one, which is lower than the $80 \mathrm{~km} / \mathrm{h}$ one.

It can be seen from Table 3 that reducing the speed from $120 \mathrm{~km} / \mathrm{h}$ to $100 \mathrm{~km} / \mathrm{h}$ can reduce the length of dangerous sections by $39.6 \%$ and lowering the speed from $100 \mathrm{~km} / \mathrm{h}$ to $80 \mathrm{~km} / \mathrm{h}$ can decrease the length by $93.8 \%$. For driving safety, the speed limit should be controlled within $80 \mathrm{~km} / \mathrm{h}$ to ensure that the vehicle will not skid. Therefore, the risk of rutted road sections can be effectively avoided through vehicle speed control.

\section{Conclusions}

Based on the CarSim software, this paper established a 3D model of the water-filled rut-adhesion coefficient-vehicle. In this model, the inputs include the rut water depth and the adhesion coefficient between the tire and the water-accumulated road surface calculated by the 3D tire-road finite element model; the safety evaluation index is the slip time to reach the dangerous lateral offset, and the threshold of slip time is the driver's critical reaction time. An experiment was designed to 
analyze the impact of the water depth difference on the safety of the water-filled rut, and a safety prediction model for the water-filled rut was established.

(1) It is found from comparison that the lengths of dangerous road sections obtained by the slidingbased method proposed in this paper are larger than those by the hydroplaning-based method. The hydroplaning-based approach underestimates the dangerous road length by $9.4 \%-100 \%$, which is likely to result in insufficient maintenance and vehicle skidding.

(2) The safety analysis was carried out on the actual water-filled ruts. The simulation results showed that, as the vehicle speed dropped from $120 \mathrm{~km} / \mathrm{h}$ to $80 \mathrm{~km} / \mathrm{h}$, the length of dangerous sections based on vehicle skidding decreased by $93.8 \%$. For driving safety, the speed limit should be controlled within $80 \mathrm{~km} / \mathrm{h}$ to ensure that the vehicle will not slip.

This paper mainly analyzed the influence of the rut's lateral shape on the safety of the water-filled rut from vehicle sliding and clustered the unsafe rutted sections in the driving direction. This paper failed to consider the impact of the longitudinal variation in the rut profile on the vehicle's braking, which can be further studied.

\section{Data Availability}

The data used to support the findings of this study are included within this article.

\section{Conflicts of Interest}

The authors declare that they have no conflicts of interest regarding the publication of this paper.

\section{Acknowledgments}

This work was sponsored by the Key Laboratory of Transport Industry of Management, Control and Cycle Repair Technology for Traffic Network Facilities in Ecological Security Barrier Area (Inner Mongolia Transport Development Research Center), Grant no. 2019KFJJ-004, Key Research and Development Program of Shaanxi (Program no. 2020ZDLGY16-01), College-Level Research Fund of Xi'an Aeronautical University (Grant no. 2020KY0220), Open Fund of Key Laboratory for Special Area Highway Engineering of Ministry of Education (Chang'an University) (300102210504), the Science and Technology Planning Project of Xi'an (2020KJRC0046), and Natural Science Foundation of Shaanxi Province (2021JQ-857).

\section{References}

[1] J. Kamplade, "Analysis of transverse unevenness with respect to traffic safety," Surface Characteristics of Roadways: International Research and Technologies: Symposium on Surface Characteristics, pp. 211-223, ASTM International, West Conshohocken, PA, USA, 1990.
[2] L. Yu, "Summarization to influence of roadway surface discontinuities on safety," China Science and Technology Information, 2013.

[3] J. C. Burns, "Differential friction: a potential skid hazard," Transportation Research Record, pp. 46-53, 1976.

[4] Florida DOT District Three selects Atkins to engineer multilane reconstruction of State Road 77. https://www.atkinsglo bal.com/en-gb/media-centre/news-releases/2013/north-amer ica/florida-dot-district-three-selects-atkins-to-engineer-multi -lane-reconstruction-of-state-road-77.\%202013.

[5] F. Li, "A methodology for characterizing pavement rutting condition using emerging 3D line laser imaging technology," $\mathrm{Ph}$. D. thesis, Georgia Institute of Technology, Atlanta, GA, USA, 2012.

[6] L. Chu, "Incorporation of functional considerations in highway pavement designand operations," Ph. D. thesis, National University of Singapore, Singapore, Singapore, 2017.

[7] T. F. Fwa, L. Chu, and K. H. Tan, "Rational procedure for determination of rut depth intervention level in network-level pavement management," Transportation Research Record Journal of the Transportation Research Board, vol. 2589, no. 2589, pp. 59-67, 2016.

[8] W. T. Luo, "Pavement hydroplaning risk evaluation with inertial measurement unit (IMU) and $1 \mathrm{~mm}$ 3D texture Data," Ph. D. Thesis, Oklahoma State University, Stillwater, OK, USA, 2015.

[9] J. Xu, Q. Peng, and Y. Shao, "Mechanism analysis of vehicle accident on surface gathered water in straight sections," China Journal of Highway and Transport, vol. 22, no. 1, pp. 97-103, 2009.

[10] F. Han, S. Yang, and Y. Lu, "Simulation analysis of the influence of road surface characteristics mutation on vehicle safety," Journal of Shijiazhuang Tiedao University (Natural Science Edition), vol. 30, no. 2, pp. 37-45, 2017.

[11] A. L. Browne, "Mathematical analysis for pneumatic tire hydroplaning," in Surface Texture Verses Skidding: Measurements, Frictional Aspects, and Safety Features of TirePavement Interaction. ASTM STP 583, J. G. Rose, Ed., American Society for Testing and Materials, West Conshohocken, PA, USA, pp. 75-94, 1975.

[12] A. Simpson, "Characterization of transverse profile," Transportation Research Record: Journal of the Transportation Research Board, vol. 1655, pp. 185-191, 1999.

[13] T. F. Fwa, H. R. Pasindu, and G. P. Ong, "Critical rut depth for pavement maintenance based on vehicle skidding and hydroplaning consideration," Journal of Transportation Engineering, vol. 138, no. 4, pp. 423-429, 2011.

[14] X. Guo, "A methodogy for rutting measurement using emerging 3D line laser imaging technology and study on rut indicators for pavement maintenance based on driving safety and hydroplaning consideration," Ph. D. Thesis, Chang'an University, Xi'an, China, 2015.

[15] H. Zhang, "Study on braking behavior moist or water asphalt of typical vehicle under pavement condition," $\mathrm{Ph}$. D. Thesis, Southeast University, Dhaka, Bangladesh, 2016.

[16] Mechanical Simulation. CARSIM: Math Models. http://www. CarSim.com/products/CarSim/models.php.\%202018.

[17] H. H. Kim and J. Ryu, "Sideslip angle estimation considering short-duration longitudinal velocity variation," International Journal of Automotive Technology, vol. 12, no. 4, pp. 545-553, 2011.

[18] H. Lee, K. Park, T. Hwang et al., "Development of enhanced ESP system through vehicle parameter estimation," Journal of Mechanical Science and Technology, vol. 23, no. 4, pp. 10461049, 2009. 
[19] Z. Yu, Automobile Theory, Machinery Industry Press, Beijing, China, 2000.

[20] Q. Cao, X. Liu, X. Huang et al., "Coupling effect of hydroplaning and road alignment on vehicle stability simulation analysis," in Proceedings of the ICPT 2017, Leuven, Belgium, August 2017.

[21] M. Pilgrim, The impact of differential friction on curve negotiation speed, University of Canterbury Engineering, Christchurch, New Zealand, 2014.

[22] K. Tomiyama, A. Kawamura, A. Yiming et al., "Basic study of rut shape characteristics in consideration of vehicle dynamics," in Proceedings of the 5th International Conference on Maintenance and Rehabilitation of Pavements and Technological Control, Park City, Utah, USA, August 2007.

[23] W. Guo, Dynamic Analysis of Coupled Road Vehicle and Long Span Cable-Stayed Bridge Systems under Cross winds, Hong Kong Polytechnic University, Hong Kong, China, 2003.

[24] 1. Ma, W. Han, J. Liu, and J. Li, "Critical wind velocities for several kinds of typical vehicle running on a cable-stayed bridge deck," Journal of Vibration and Shock, vol. 30, no. 10, pp. 30-34, 2011.

[25] W. Han and A. Chen, "Safety assessment of moving vehicles on a long-span bridge unber crosswind and influence factors analysis," Acta Aerodynamica Sinica, vol. 26, no. 4, pp. 466$472,2008$.

[26] W. Han, L. Ma, S. Yuan, A. Chen, and J. Liu, "Probability analysis of bridge deck side wind-induced vehicle accidents based on joint distribution of wind speed and wind direction," China Journal of Highway and Transport, vol. 23, no. 2, pp. 43-49, 2010.

[27] J. Lu, L. Zhu, R. Zheng, and Y. Wei, "Effects of driver's reaction time on safe driving," Journal of Transportation Systems Engineering and Information Technology, vol. 14, no. 2, pp. 80-86, 2014.

[28] J. Xu and J. Wu, "Harsh environment influence on drivers' response time," Transport Standardization, vol. 23, pp. 103$106,2009$. 